\title{
Clinicopathological study of hysterectomised specimens
}

\author{
Saravana A. ${ }^{1}$, Shashikala B. Patil ${ }^{1}$, Savitha S. Patil ${ }^{2}$ \\ ${ }^{1}$ Department of Obstetrics and Gynecology, BGS Global Institute of Medical Sciences, Bengaluru, Karnataka, India \\ ${ }^{2}$ Department of Community Medicine, BGS Global Institute of Medical Sciences, Bengaluru, Karnataka, India
}

Received: 08 November 2016

Accepted: 03 December 2016

\section{*Correspondence:}

Dr. Shashikala B. Patil,

E-mail:drshashika@gmail.com

Copyright: ( $\odot$ the author(s), publisher and licensee Medip Academy. This is an open-access article distributed under the terms of the Creative Commons Attribution Non-Commercial License, which permits unrestricted non-commercial use, distribution, and reproduction in any medium, provided the original work is properly cited.

\begin{abstract}
Background: Hysterectomy is the commonest major surgical procedure performed in gynecology. It can be done by abdominal or vaginal route and with the help of laparoscopy. Hysterectomy is an effective treatment option for many conditions like fibroid, abnormal uterine bleeding, endometriosis, adenomyosis, uterine prolapse, pelvic inflammatory disease and cancer of reproductive organ when other treatment options are contraindicated or have failed, or if the woman no longer wishes to retain her menstrual and reproductive. The aim and objective of the study was to correlate indications of hysterectomy with histopathological findings in hysterectomised patients.

Methods: A retrospective study was carried on 113 hysterectomised cases over a period of one year from June 2015 to May 2016. The data regarding the patient's age, parity, clinical diagnosis, type of hysterectomy and histopathological diagnosis were reviewed by the records and analyzed.

Results: A total of 113 cases of hysterectomies were studied. Hysterectomies were distributed over a wide age ranging from 20 years to 75 years. Most common age group was 41-50 years. Among hystectomies majority were done through vaginal route $86(76.1 \%)$ and $26(23 \%)$ cases were done through abdominal route. Most common clinical diagnosis was fibroid uterus in 44(38.9\%) cases. Most of the hysterectomies were done for benign conditions. In final histopathological report most common diagnosis was fibroid uterus in $45(39.8 \%)$ hysterectomy specimens. It was correlated well with clinical diagnosis. Next most common histopathological diagnosis was Adenomyosis.

Conclusions: Histopathological analysis correlated well with preoperative clinical diagnosis in majority of cases. The commonest indication and histopathological finding in our study was fibroid uterus. Next most common histopathological finding was Adenomyosis. Most commonly hysterectomies were done through vaginal route in our study.
\end{abstract}

Keywords: Hysterectomy, Laparoscopy, Vaginal

\section{INTRODUCTION}

Hysterectomy is the commonest major surgical procedure performed in gynaecology. It can be done by abdominal or vaginal route and with the help of laparoscopy. The latest value study concluded that major haemorrhage, hematoma, ureteric injury, bladder injury, and anaesthetic complications were more in laparoscopic assisted hysterectomy (LAVH) group when compared to abdominal and vaginal hysterectomies.
In addition LAVH was accomplished in twice the time required for vaginal hysterectomy. ${ }^{1}$ Hysterectomy is an effective treatment option for many conditions like fibroid, abnormal uterine bleeding, endometriosis, adenomyosis, uterine prolapse, pelvic inflammatory disease and cancer of reproductive organ when other treatment options are contraindicated or have failed, or if the woman no longer wishes to retain her menstrual and reproductive function. About $70-80 \%$ of hysterectomies are performed by the abdominal approach. ${ }^{2}$ Fibroids are 
the most common indication $(39 \%)$ cited for performance of hysterectomy. ${ }^{3}$

The aim and objective of the study was to correlate indications of hysterectomy with histopathological findings in hysterectomised patients.

\section{METHODS}

The study was approved by the Institutional Ethics and Research Committee of medical college and hospital Bangalore. A retrospective study carried on 113 hysterectomised cases over period of one year from June 2015 to May 2016. The data regarding the patient's age, parity, clinical diagnosis, type of hysterectomy and histopathological diagnosis were reviewed by the records and analysed.

\section{Statistical analysis}

The data collected was tabulated in SPSS. Descriptive statistics like frequencies and percentages were enumerated for all categorical variables such as age, parity etc., Mean \pm SD (Standard deviation) was calculated. Correlation of clinical diagnosis and histopathological diagnosis was done. $\mathrm{P}$ value $\leq 0.05$ was considered as statistically significant. All statistical analyses were performed using the SPSS statistical package, version 17.0 (SPSS).

\section{RESULTS}

Table 1: Frequency distribution of age and parity.

\begin{tabular}{|c|c|c|c|c|c|c|}
\hline \multirow[b]{2}{*}{ Parity } & \multicolumn{5}{|c|}{ Age in years } & \multirow{2}{*}{$\begin{array}{l}\text { Total } \\
\mathbf{n}(\%)\end{array}$} \\
\hline & $20-30$ & $31-40$ & $41-50$ & $51-60$ & $\geq 61$ and above & \\
\hline 1 & 2 & 5 & 7 & 0 & 0 & $14(12.4)$ \\
\hline 2 & 1 & 25 & 26 & 6 & 0 & $58(51.3)$ \\
\hline 3 & 0 & 8 & 12 & 5 & 2 & $27(23.9)$ \\
\hline$\geq 4$ & 0 & 0 & 5 & 4 & 5 & $14(12.4)$ \\
\hline Total n (\%) & $3(2.6)$ & $38(33.6)$ & $50(44.3)$ & $15(13.3)$ & $7(6.2)$ & 113 \\
\hline Mean parity $2.4 \pm 1.60$ & \multicolumn{6}{|c|}{ Mean age of the patient $43 \pm 2.60$ years } \\
\hline
\end{tabular}

Table 2: Type of hysterectomy.

\begin{tabular}{|ll|}
\hline Type of hysterectomy & Total N=113 N (\%) \\
\hline NDVH & $69(61.1)$ \\
\hline $\begin{array}{l}\text { NDVH with unilateral } \\
\text { Salpingooophorectomy }\end{array}$ & $2(1.8)$ \\
\hline VH with PFR & $15(13.3)$ \\
\hline TAH & $9(8.0)$ \\
\hline TAH with BSO & $13(11.5)$ \\
\hline $\begin{array}{l}\text { TAH with unilateral } \\
\text { Salpingooophorectomy }\end{array}$ & $4(3.5)$ \\
\hline NDVH converted to TAH & $1(0.9)$ \\
\hline Total no $(\%)$ & $113(100)$ \\
\hline
\end{tabular}

A total of 113 cases of hysterectomies were studied. Hysterectomies were distributed over a wide age ranging from 20 years to 75 years. Most common age group was 41-50 years; next most common age group was 31-40 years. Most of the cases were parous women. Majority were with para 2 (Table 1).

Among hystectomies majority were done through vaginal route $86(76.1 \%)$ and $26(23 \%)$ cases were done through abdominal route. In one case vaginal hysterectomy was converted to abdominal route. It was a case of 16 weeks fibroid uterus. Among total of 86 vaginal hysterectomies 15 cases were done for prolapse uterus and remaining 71 cases NDVH (nondescent vaginal hysterectomy) was done for DUB, fibroid uterus etc.

Table 3: Clinical diagnosis.

\begin{tabular}{|ll|}
\hline Clinical diagnosis & Frequency (\%) \\
\hline Fibroid uterus & $44(38.9)$ \\
\hline $\begin{array}{l}\text { Dysfunctional uterine } \\
\text { bleeding }\end{array}$ & $37(32.7)$ \\
\hline Prolapse uterus & $15(33.0)$ \\
\hline Adenomyosis & $9(8.0)$ \\
\hline Post-menopausal bleeding & $2(1.8)$ \\
\hline Chronic PID & $1(0.9)$ \\
\hline CIN & $2(1.8)$ \\
\hline Carcinoma cervix & $1(0.9)$ \\
\hline Carcinoma endometrium & $2(1.8)$ \\
\hline Ovarian cyst & $1(0.9)$ \\
\hline Pyometra & $2(1.8)$ \\
\hline
\end{tabular}

Most of the hysterectomies were done for benign conditions. 3 cases of malignancy and 3 cases CIN was diagnosed preoperatively. Most common clinical diagnosis was fibroid uterus in $44(38.9 \%)$ cases. Next most common was DUB in 37 (32.7) cases (Table 3).

In final histopathological report most common diagnosis was fibroid uterus in 45(39.8\%) hysterectomy specimens. 
It was correlated well with clinical diagnosis. Next most common histopathological diagnosis was Adenomyosis. Among 37 cases of DUB 16 cases were diagnosed on HPR as Adenomyosis. Proliferative endometrium was diagnosed in 2 cases of postmenopausal bleeding cases. Two cases of CIN were diagnosed as chronic cervicitis in final report. There was one case carcinoma cervix and 2 cases of endometrial adenocarcinoma (Table 4).

Table 4: Histopathology report.

\begin{tabular}{|ll|}
\hline HPR diagnosis & Frequency (\%) \\
\hline Fibroid uterus & $45(39.8)$ \\
\hline Adenomyosis & $25(22.1)$ \\
\hline $\begin{array}{l}\text { Endometrial hyperplasia } \\
\text { Proliferative endometrium } \\
\text { Secretory endometrium }\end{array}$ & $23(20.3)$ \\
\hline Atrophic endometrium & $12(10.6)$ \\
\hline Endometrial adenocarcinoma & $2(1.8)$ \\
\hline Chronic endometritis & $2(1.8)$ \\
\hline Chronic cervicitis & $2(1.8)$ \\
\hline Endometrial polyp & $1(0.9)$ \\
\hline Carcinoma cervix & $1(0.9)$ \\
\hline
\end{tabular}

\section{DISCUSSION}

A retrospective study carried on 113 hysterectomised cases over period of one year from June 2015 to May 2016. The data regarding the patient's age, parity, clinical diagnosis, type of hysterectomy and histopathological diagnosis were reviewed by the records and analysed.

Hysterectomies were distributed over a wide age ranging from 20 years to 75 years. Most common age group was 41-50 years. Similar age group was seen in hysterectomy cases, study by Shergill SK et al. ${ }^{4}$ Most of the cases were parous women. Majority were with para 2.

Among hystectomies majority were done through vaginal route $86(76.1 \%)$, and $26(23 \%)$ cases were done through abdominal route. In one case vaginal hysterectomy was converted to abdominal route. It was a case of 16 weeks fibroid uterus, a case of degenerated multiple fibroids. Vaginal route of hysterectomy is the safe route of hysterectomy. Advantages of doing nondescent vaginal hysterectomy over abdominal hysterectomy are due to no scar, no adhesions, no hernia, no wound gap, associated urogynec procedures can also be performed, less operative time, less blood loss, less anaesthetics complications, largely extraperitoneal dissection to prevent injury to bowel, bladder and ureter, minimal bowel handling - no paralytic ileus, shorter hospital stay, fast recovery, low cost, less thromboembolic phenomena, less mortality and morbidity, natural, simple route for drainage. Urinary tract injury is also less common in nondescent vaginal hysterectomy than other routes. 5,6
Most of the hysterectomies were done for benign conditions. Most common indication being fibroid uterus $44(38.9 \%)$, similar to study by Shergill SK et al. ${ }^{4} \mathrm{Next}$ most common indication was DUB 37 (32.7\%). 3 cases of malignancy and 3 cases of CIN were diagnosed preoperatively.

In final histopathological report most common diagnosis was fibroid uterus in 45(39.8\%) hysterectomy specimens. It was correlated well with clinical diagnosis. Next most common histopathological diagnosis was Adenomyosis. Among 37 cases of DUB 16 cases were diagnosed on HPR as Adenomyosis. Proliferative endometrium was diagnosed in 2 cases of postmenopausal bleeding cases. Two cases of CIN were diagnosed as chronic cervicitis in final report. There was one case carcinoma cervix in situ and 2 cases of endometrial adenocarcinoma. In final histopathological report most common diagnosis was fibroid uterus in 45 (39.8) hysterectomy specimens. It was correlated well with clinical diagnosis. Next most common histopathological diagnosis was Adenomyosis.

\section{CONCLUSION}

Histopathological analysis correlated well with preoperative clinical diagnosis in majority of cases. The commonest indication and histopathological finding in our study was fibroid uterus. Next most common histopathological finding was Adenomyosis. Most commonly hysterectomies were done through vaginal route $86(76.1 \%)$ in our study.

\section{Funding: No funding sources \\ Conflict of interest: None declared \\ Ethical approval: Not required}

\section{REFERENCES}

1. Choosing the route for hysterectomy for benign disease. ACOG committee opinion. The American college of obstetricians and Gynecologists. 2009:444.

2. Begum J, Talukder SI, Hossain MA. A two years audit of complications of total abdominal hysterectomy at Dinajpur Medical College Hospital Dinajpur. Med Col J. 2008;1(1):14-7.

3. Whiteman MK, Hillis SD, Jamieson D. Inpatient hysterectomy surveillance in the United States, 20002004. Am J Obstet Gynecol. 2008:31-37.

4. Shergill SK, Shergill HK, Gupta M, Kaur S. Clinicopathological study of hysterectomies. J Indian Med Assoc. 2002;100(4):238-9, 246.

5. Schwarz R. choice of surgical route in hysterectomy: Gynekol Rundsch. 1990;30(4):248-52.

6. Del Frat G, Soligo M. Vaginal and abdominal hysterectomy: comparison and perspectives: Minerva Gynaecology. 1996;48(5):181-91.

Cite this article as: Saravana A, Patil SB, Patil SS. Clinicopathological study of hysterectomised specimens. Int J Reprod Contracept Obstet Gynecol 2017;6:246-8. 